the orifice. ${ }^{5}$ Posterior veins are also referred to as inferolateral collaterals and left posterior veins. The coronary sinus venograms obtained during the treatment of patient 2 were not preserved. Echocardiograms demonstrate the lead entering the coronary sinus but do not define the final venous location. It is likely that the vein used in the treatment of patient 1 was a posterior vein, whereas the vein used in the treatment of patient 2 was a posterior or middle cardiac vein. Because the primary objective of lead insertion in these patients was ventricular pacing and not cardiac resynchronization therapy, the precise location of the veins involved is primarily of academic interest.

\section{CONCLUSIONS}

The middle and posterior cardiac veins provide access for ventricular pacing as an alternative to thoracotomy when passing a lead across the tricuspid annulus is contraindicated.
Access through these veins should be considered in patients with complicated surgical heart disease that includes a history of previous thoracotomy.

\section{References}

1. Giraldi F, Cattadori G, Roberto M, Carbucicchio C, Pepi M, Ballerini G, et al. Long-term effectiveness of cardiac resynchronization therapy in heart failure patients with unfavorable cardiac veins anatomy comparison of surgical versus hemodynamic procedure. J Am Coll Cardiol. 2011;58:483-90.

2. Goldstein DJ, Rabkin DG, Spotnitz HM. Unconventional approaches to cardiac pacing in patients with inaccessible cardiac chambers. Ann Thorac Surg. 1999; 67:952-8.

3. Nguyen LS, Swaroop S, Prejean CA. Pacing in the middle cardiac vein in a patient with tricuspid prosthesis. Pacing Clin Electrophysiol. 2002;25:243-4.

4. Hansky B, Güldner H, Vogt J, Minami K, Tenderich G, Horstkotte D, et al Coronary vein leads for cardiac pacing in patients with tricuspid valve replacement. Thorac Cardiovasc Surg. 2002;50:120-1.

5. Meisel E, Pfeiffer D, Engelmann L, Tebbenjohanns J, Schubert B, Hahn S, et al. Investigation of coronary venous anatomy by retrograde venography in patients with malignant ventricular tachycardia. Circulation. 2001;104: 442-7.

\title{
Early experience with the transaortic approach for transcatheter aortic valve implantation
}

\author{
Gopal Soppa, MRCS, PhD, David Roy, MD, Stephen Brecker, FRCP, and Marjan Jahangiri, FRCS (CTh), \\ London, United Kingdom
}

Transcatheter aortic valve implantation (TAVI) for the treatment of severe aortic stenosis (AS) is an increasingly viable option for patients at high risk or with contraindications for surgical aortic valve replacement (SAVR). ${ }^{1} \mathrm{TAVI}$ improves survival and quality of life in high-risk patients with severe AS compared with medical therapy and is comparable with SAVR. ${ }^{1}$ The transfemoral (TF) approach is the most common access route for deploying balloonexpandable valves. Alternative access routes in patients with severe peripheral vasculopathy include the transapical (TA), ${ }^{2}$ transaxillary (TAx), and, recently, the transaortic (TAo) approaches. ${ }^{3}$ We describe our early experience with the TAo approach.

\footnotetext{
From the Department of Cardiothoracic Surgery and Cardiology, St George's Hospital, University of London, London, United Kingdom.

Disclosures: Authors have nothing to disclose with regard to commercial support.

Received for publication Sept 14, 2011; revisions received Oct 20, 2011; accepted for publication Oct 31, 2011; available ahead of print Dec 12, 2011.

Address for reprints: Marjan Jahangiri, FRCS (CTh), Department of Cardiothoracic Surgery, St George's Hospital, Blackshaw Rd, London SW17 0QT, United King-

dom (E-mail: Marjan.Jahangiri@stgeorges.nhs.uk).

J Thorac Cardiovasc Surg 2012;143:1225-7

$0022-5223 / \$ 36.00$

Copyright (c) 2012 by The American Association for Thoracic Surgery

doi:10.1016/j.jtcvs.2011.10.082
}

\section{CLINICAL SUMMARY}

Between February and August 2011, 12 patients underwent TAVI with the TAo approach. Patients at high risk for SAVR are referred to a multidisciplinary meeting, where some will be scheduled to undergo surgical intervention, TAVI, or only medical treatment. ${ }^{4}$ Our method of approach for TAVI in the last 3 years has been primarily the TF approach or, if this is not possible, the TAx or TA approaches. However, because of the well-established minimally invasive SAVR procedure through a limited sternotomy ${ }^{5}$ in our unit and some of the complications associated with the TF approach, as well as the unsuitability of some patients for a peripheral approach, we started using the TAo technique.

After achievement of general anesthesia, a temporary pacing wire is placed through the internal jugular vein. A limited J-sternotomy into the third intercostal space is sufficient because access to the right atrium is not required. The proximal aorta is exposed, and a "soft" point for aortic puncture is identified by means of palpation and use of a metal marker under fluoroscopic guidance (Figure 1, $A$ ). This point is at least $6 \mathrm{~cm}$ above and in direct line with the aortic valve $(\mathrm{AV}$; Figure $1, B)$. Two purse-string sutures with Teflon pledgets are placed, and aortic puncture is performed. After crossing the AV by using the Seldinger 


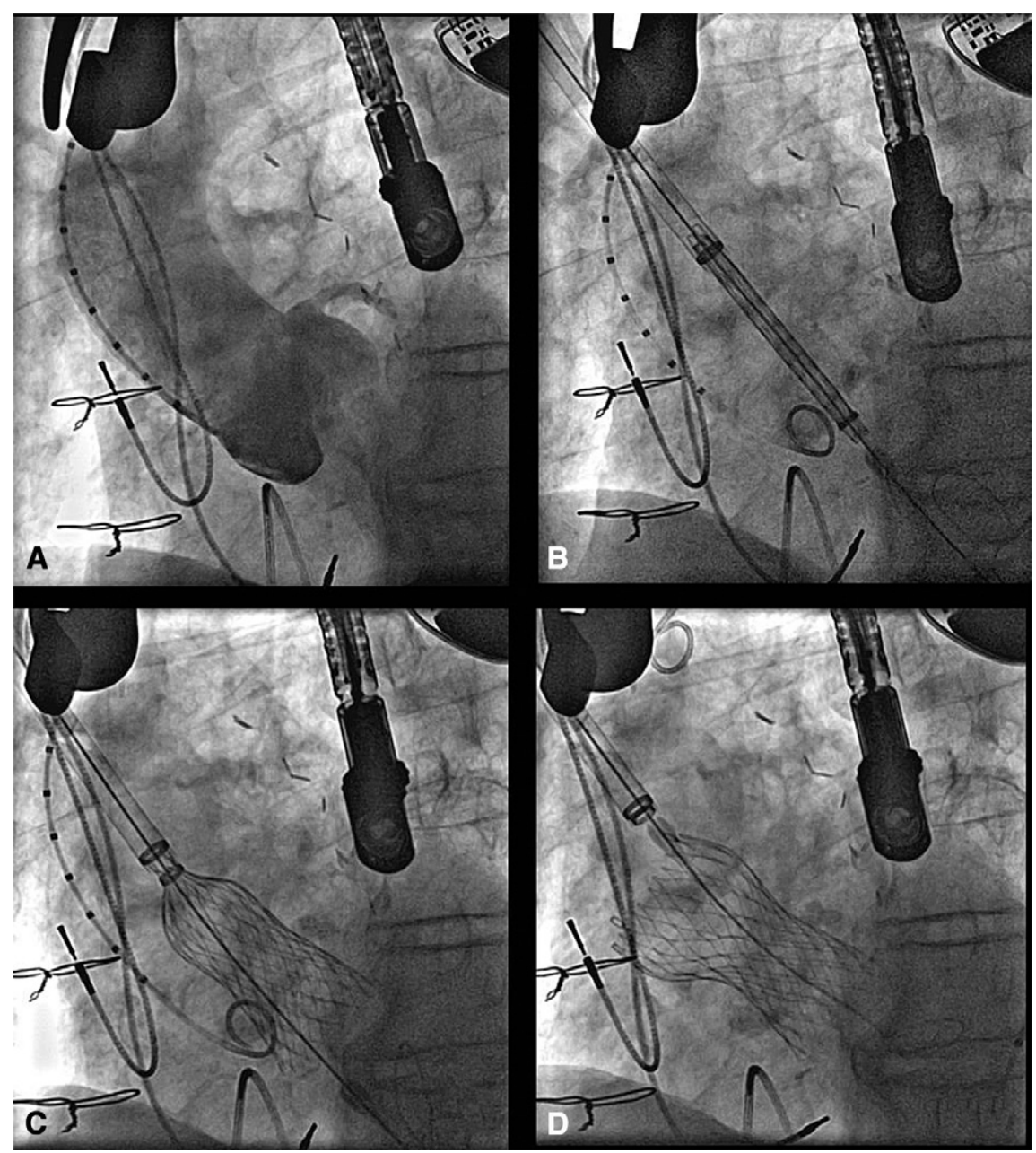

FIGURE 1. A metal marker (A) is placed to identify a suitable point on the ascending aorta at least $6 \mathrm{~cm}$ above and in direct line with the aortic valve. After balloon valvuloplasty, the sheath and valve are introduced in a straight line (B), and the valve is deployed (C and D).

technique, a balloon valvuloplasty is performed during rapid pacing. The valve sheath is then inserted into the aorta and retracted sufficiently, particularly for the Corevalve Revalving System (Medtronic, Minneapolis, Minn) with a long introducer, and the valve is deployed (Figure 1, $C$ and $D$ ).

Twelve patients with a median age of $82.2 \pm 7.0$ years (range, 77-87 years) and a median EuroSCORE of $18 \pm 4$ underwent TAVI. One patient had undergone coronary artery bypass grafting with a patent left internal thoracic artery and vein grafts, 1 patient had a heavily calcified aorta (an appropriate aortic puncture site was identified), 4 patients had significant peripheral vasculopathy (femoral vessels $<6 \mathrm{~mm}$ ), and 3 patients had severe chronic obstructive pulmonary disease (COPD). Ten patients had Corevalve implantation, and 2 underwent Edwards Sapien THV valve (Edwards Lifesciences, Irvine, Calif) implantation. The mean procedure time was 66 minutes (range, 46-90 minutes), and all patients were extubated within 4 hours after the procedure. One patient required a permanent pacemaker, and none had a stroke. One patient died 3 days after the procedure of perforation of the right ventricle caused by the temporary pacing wire. The median hospital stay was 7 days (range, 5-11 days). Transthoracic echocardiographic analysis at discharge and 3 months showed a mild paravalvular leak in 2 patients.

\section{DISCUSSION}

Our early experience with the TAo approach demonstrates intraprocedural safety in high-risk patients with AS, including those with patent grafts, a calcified aorta, severe COPD and peripheral vasculopathy. The main advantages are a direct straight-line approach to the $\mathrm{AV}$ with no angles, less instrumentation of the aortic arch, a familiar approach for surgeons, technical skills that can be acquired with minimal training, less invasiveness, and feasibility of conversion to a full sternotomy. The aortic puncture site is well above the proximal coronary anastomoses in the case of patients undergoing redo procedures. In patients with patchy aortic calcification, a "soft" point 
of entry can be established with a combination of computed tomographic scanning, echocardiographic analysis, aortographic analysis, and digital palpation. Use of epiaortic scanning can be cumbersome through a small incision. In patients with COPD, chest wall integrity provided by a partial sternotomy sustains efficient ventilation when combined with effective postoperative analgesia. Absolute contraindications for the TAo approach are "porcelain" aorta and previous sternal wound infection with chest wall reconstruction.

The TF approach is associated with $11 \%$ major vascular complications, ${ }^{1}$ and the TA approach is associated with site-specific complications, such as left ventricular bleeding, hypokinesia/akinesia of the apex, and aneurysm formation. ${ }^{2}$ Stroke remains a significant problem after TAVI compared with SAVR $(5.1 \%$ vs $2.4 \%) .{ }^{1,2}$ Various mechanisms of stroke during TAVI include crossing the AV with guide wires, instrumentation of arch atheroma, balloon valvuloplasty, pigtail catheter thrombosis, valve deployment, and postdilatation balloon valvuloplasty. The
TAx approach does not eliminate crossing the aortic arch or its instrumentation, and the approach to the $\mathrm{AV}$ is at an angle that can be cumbersome. The TAo approach minimizes instrumentation of arch atheroma and might reduce the risk of stroke. The TAo approach provides a safe and feasible technique through a familiar route for surgeons.

\section{References}

1. Smith CR, Leon MB, Mack MJ, Miller DC, Moses JW, Svensson LG, et al. Transcatheter versus surgical aortic-valve replacement in high-risk patients. $N$ Engl J Med. 2011;364:2187-98

2. Walther T, Kempfert J, Rastan A, Borger MA, Linke A, Ender J, et al. Transapical aortic valve implantation at 3 years. J Thorac Cardiovasc Surg. 2011 [Epub ahead of print].

3. Bapat V, Khawaja MZ, Attia R, Narayana A, Wilson K, Macgillivray K, et al Transaortic transcatheter aortic valve implantation using Edwards Sapien valve: a novel approach. Catheter Cardiovasc Interv. 2011 [Epub ahead of print]

4. Jahangiri M, Laborde JC, Roy D, Williams F, Abdulkareem N, Brecker S. Outcome of patients with aortic stenosis referred to a multidisciplinary meeting for transcatheter valve. Ann Thorac Surg. 2011;91:411-5.

5. Tabata M, Umakanthan R, Cohn LH, Bolman RM III, Shekar PS, Chen FY, et al. Early and late outcomes of 1000 minimally invasive aortic valve operations. Eur J Cardiothorac Surg. 2008;33:537-41.

\title{
Carotid artery and jugular vein cannulation in aortic redo surgery
}

\author{
Paul P. Urbanski, MD, PhD, Bad Neustadt, Germany
}

Aneurysms that develop after previous aortic surgery pose a high risk of massive hemorrhage during reopening of the thorax, and therefore a femorofemoral cannulation and deep hypothermia are usually recommended before sternotomy. ${ }^{1,2}$ Here, an alternative approach with arterial cannulation of the common carotid artery through a vascular side graft and venous cannulation of the jugular vein is presented.

From the Cardiovascular Clinic Bad Neustadt, Bad Neustadt, Germany.

Disclosures: Dr Urbanski discloses a financial relationship with MAQUET Cardiovascular, Inc.

Received for publication July 1, 2011; accepted for publication Oct 31, 2011; available ahead of print Dec 12, 2011.

Address for reprints: Paul P. Urbanski, MD, PhD, Herz- und Gefaess-Klinik, Salzburger Leite 1, 97616 Bad Neustadt, Germany (E-mail: p.urbanski@herzchirurgie.de). J Thorac Cardiovasc Surg 2012;143:1227-9

$0022-5223 / \$ 36.00$

Copyright (c) 2012 by The American Association for Thoracic Surgery doi:10.1016/j.jtcvs.2011.10.083

\section{CLINICAL SUMMARY}

For the approach to the right common carotid artery and the right jugular vein, an incision was made on the neck along the margin of the sternocleidomastoid muscle before the median sternotomy. The neck vessels were isolated, and after heparinization, the common carotid artery was crossclamped, a longitudinal incision was made, and an 8- or 10-mm vascular prosthesis (InterGard; InterVascular, MAQUET Cardiovascular, La Ciotat, France) was anastomosed to the artery with a continuous 5-0 Prolene suture, as described in detail previously. ${ }^{3,4}$ The jugular vein was cannulated by using the Seldinger technique. For this purpose, intraoperative transesophageal echocardiographic analysis was performed in all patients to ensure echocardiographic guidance for correct positioning of the venous cannula. First, the guide was introduced into the inferior vena cava under transesophageal echocardiographic guidance, and then the femoral venous cannula (Edwards Lifesciences LLC, Irvine, Calif) was placed (Video 1). In one case with additional mitral valve surgery, we used a dual-stage cannula (Estech, San Ramon, Calif) for cannulation.

The resternotomy was not performed until establishment of cardiopulmonary bypass, achievement of mild hypothermia, and decrease in blood pressure to about $60 \mathrm{~mm} \mathrm{Hg}$. 